\title{
Dinâmica da cobertura vegetal para a Bacia de São João do Rio do Peixe, PB, utilizando-se sensoriamento remoto
}

\author{
John E. de B. L. Cunha ${ }^{1}$, Iana A. A. Rufino ${ }^{2}$, \\ Bernardo B. da Silva ${ }^{3} \&$ lêde de B. Chaves ${ }^{4}$
}

\begin{abstract}
RESU M O
De modo geral, a cobertura vegetal do semiárido paraibano se encontra bastante antropizada; exemplo disto é a bacia hidrográfica do Rio do Peixe, totalmente inserida na região semiárida do $\mathrm{N}$ ordeste brasileiro a qual tem sofrido, ao longo dos anos, as consequências da ocupação humana. N este contexto, o presente trabalho tem como objetivo realizar uma análise multitemporal de variáveis biofísicas derivadas de imagens do satélite Landsat 5 e técnicas de processamento digital de imagens e geoprocessamento, para o período de 23 anos. $0 \mathrm{~s}$ resultados apontam para uma recuperação da cobertura vegetal, mais evidente nos trechos mais declivosos da bacia hidrográfica, fato relacionado ao êxodo da população rural ocorrido no período de estudo. Ficou patente, também, que o albedo da superfície foi o parâmetro que melhor se correlacionou com as variações da biomassa vegetal. Contudo, as variações da cobertura da vegetação não foram suficientes para, isoladamente, explicar as variações na temperatura da superfície e o saldo de radiação, ao longo dos anos analisados.
\end{abstract}

Palavras-chave: imagens de satélite, cobertura vegetal e processamento digital de imagens

\section{Dynamics of vegetal cover for São João do Rio do Peixe Basin (Paraíba) using remote sensing}

\begin{abstract}
AB STRACT
In general, the semiarid region of Paraíba (northeastern Brazil) the vegetation has changed due to human activities, for example, Peixe River basin, that has suffered over the years by human occupation. In this context, this paper aims to conduct a multi-temporal analysis of biophysical variables derived from images of the Landsat 5 satellite and digital image processing techniques and GIS for 23 years. The results indicated increase of vegetation specially in the high slope areas of the basin. That fact may be related to the exodus of rural population occurred during the observed period. It was also observed that the surface al bedo was best correlated parameter with changes in vegetal biomass. However, the isolated variations in vegetation cover were not enough to explain the variations in surface temperature and net radiation over the analyzed years.
\end{abstract}

Key words: satellite images, vegetal cover, and digital imageprocessing

\footnotetext{
${ }^{1}$ Mestre em Engenharia Civil e Ambiental/U FCG. E-mail: john.e.cunha@gmail.com

2 UACA/U FCG. E-mail: iana alex@uol.com.br

3 Depto. de Ciências Geográficas/U FPE. E-mail: bbdasilva.ufpe@gmail.com

${ }^{4}$ D outor em Agronomia, especialista em Manejo e Conservação do Solo e Água. E-mail: iedebchaves@hotmail.com
} 


\section{INTRODUÇÃO}

Os processos de mudanças da cobertura e uso da terra são parte das discussões globais sobre o meio ambiente, há algumas décadas. Os sistemas terrestres respondem às alterações antrópicas, causando mudanças em seus ciclos que, em resposta, vão afetar as atividades humanas (Liana \& Shimabukuro, 2007).

Técnicas de sensoriamento remoto têm sido utilizadas em estudos temporais de análise das mudanças da cobertura e uso do solo (Gómez et al., 2011; Foody, 2010). Atualmente, existem diversos sensores remotos com resoluções espaciais, temporais e espectrais diferentes que vêm sendo utilizados para compreensão desses processos (Amiri et al., 2009; Carreiras et al., 2006). Nessas aplicações o principal interesse é compreender as mudanças ocorridas na paisagem ao longo do tempo.

Os processos de análise das alterações na cobertura do solo por meio de imagens orbitais devem considerar fatores inerentes ao instrumento e período de aquisição dos dados. Os dados dos sensores orbitais são afetados pela degradação dos detectores, ângulo solar zenital, distância terra-sol, ângulo de visada do sensor, função de distribuição bidirecional da reflectância, condições atmosféricas, topografia e evolução das características do alvo (Chander et al., 2010).

Com o sensor Thematic Mapper (TM), o satélite LANDSAT 5foi lançado em 1 de março de 1984 e coleta informações sobre a superfície da terra, de forma contínua. Historicamente, este sensor vem passando por processos de revisão da sua calibração radiométrica (Chander et al., 2007; 2009; 2010; Chander \& Markam, 2003), cujos estudos contribuem para que as análises multitemporais, realizadas a partir dos dados deste sensor, não sofram influência da sua degradação evitando que mudanças detectadas nas imagens possam ser erroneamente atribuídas a alterações no alvo.

Ao longo da sua história os dados do TM têm sido utilizados em diversos estudos que objetivam compreender os processos de alteração da superfície. Imagens do TM- Landsat foram utilizadas na identificação de áreas atingidas pelo fogo em florestas (Morton et al., 2011; Röder et al., 2008), distúrbios em florestas (Schroeder et al., 2011), reflorestamento (Huang et al., 2010) e desertificação (Stellmes et al., 2010).

A precipitação é uma das principais forças motrizes para a disponibilidade de biomassa em áreas secas e por isso altamente correlacionada com a cobertura vegetal. Por reunir esta característica, o semiárido é um indicador sensível das alterações climáticas (Brinkmann et al., 2011). Mudanças no regime pluviométrico podem interferir diretamente na resposta da cobertura vegetal e, consequentemente, nos componentes do ciclo hidrológico.

Em ambientes semiáridos a análise da cobertura vegetal é complexa face ao alto grau de variabilidade interanual da precipitação. Mudanças detectadas nas propriedades físicas da superfície da terra podem ser resultado de uma elasticidade da resposta à precipitação (Bradley \& Mustard, 2005), não estando relacionadas diretamente com efeitos da ocupação humana nessas áreas.
A cobertura vegetal do semiárido paraibano se encontra bastante antropizada; na maioria das vezes algumas atividades econômicas são acompanhadas de desmatamento indiscriminado, comprometendo os recursos naturais desta região (Alves et al., 2008). Por outro lado, essas áreas vêm apresentando diminuição da população rural, o que reduz a pressão antrópica em tais ambientes.

Objetivou-se realizar, neste contexto, uma análise multitemporal, utilizando-se imagens do sensor TM do satélite Landsat 5 e técnicas de processamento digital de imagens e geoprocessamento, para o período de 23 anos.

As mudanças na cobertura da terra na Bacia do Rio do Peixe são analisadas a partir de índices de vegetação consagrados na literatura: NDVI, LAI e EVI. As respostas da superfície a essas alterações serão analisadas a partir do albedo da superfície, temperatura da superfície e saldo de radiação.

\section{Material e MÉTODOS}

A Bacia de São João do Rio do Peixe está localizada na porção noroeste do estado da Paraíba (Figura 1) e inserida na região semiárida do Nordeste do Brasil, com área de $3.419 \mathrm{~km}^{2}$, abrangendo 17 municípios.

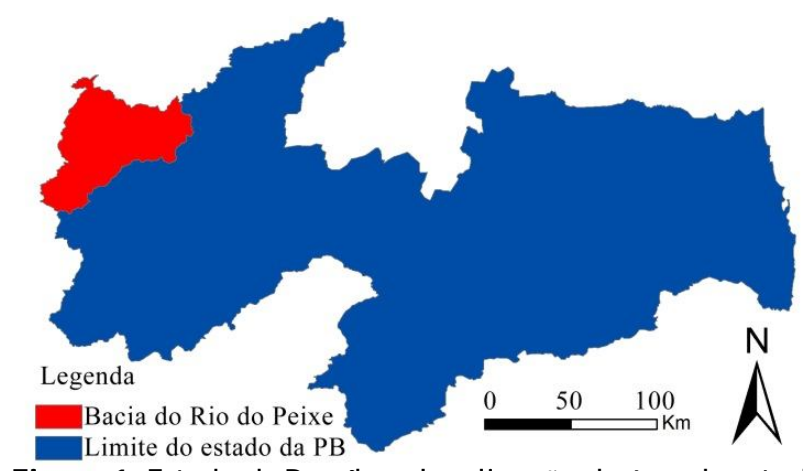

Figura 1. Estado da Paraíba e localização da área de estudo

Na Tabela 1 se apresentam as populações rural e urbana para os anos de 1991, 2000 e 2010 para os municípios localizados na Bacia do Rio do Peixe, percebendo-se decréscimo populacional na área rural e aumento da população urbana, em relação ao ano de 1991. A Figura 2 mostra a elevação do terreno, a declividade, as sedes municipais e a distribuição da rede de drenagem da bacia hidrográfica.

O clima da região de estudo, segundo a classificação de Köppen, é do tipo Aw'- Tropical quente e úmido com chuvas de verão-outono (janeiro e abril), apresentando duas estações (seca e chuvosa), com pluviometria média anual em torno de $800 \mathrm{~mm}$ (Silva et al., 1984).

Em quase toda a bacia a vegetação é do tipo caatinga hiper xerófila e os solos se apresentam com grande diversidade: mais rasos e pedregosos nas áreas mais elevadas e declivosas (Argissolo, Luvissolo e Neossolo Litólico); medianamente profundos, pedregosos, argilosos (Luvissolo, Argissolos) e arenosos (Planossolo), em relevo suave ondulado e muito argiloso e plano (Vertissolo) na bacia sedimentar cretácia, ao longo da rede principal da drenagem (Brasil, 1972). 
Tabela 1. População nos municípios que compõem a Bacia de São João do Rio do Peixe

\begin{tabular}{|c|c|c|c|c|c|c|}
\hline \multirow{2}{*}{ Cidades } & \multicolumn{2}{|c|}{1991} & \multicolumn{2}{|c|}{2000} & \multicolumn{2}{|c|}{2010} \\
\hline & Rural & Urbana & Rural & Urbana & Rural & Urbana \\
\hline Sousa & 27.069 & 52.066 & 16.435 & 46.200 & 13.922 & 51.885 \\
\hline Cajazeiras & 12.944 & 38.329 & 12.751 & 41.964 & 10.948 & 47.489 \\
\hline $\begin{array}{l}\text { São J oão do Rio } \\
\text { do Peixe }\end{array}$ & 14.644 & 6.907 & 6.066 & 11.595 & 11.316 & 6.885 \\
\hline Uiraúna & 11.196 & 8.937 & 4.735 & 8.946 & 4.235 & 10.349 \\
\hline Cachoeira dos Índios & 4.930 & 2.385 & 2.671 & 5.163 & 6.143 & 3.403 \\
\hline Aparecida & & & 2.931 & 2.963 & 4.038 & 3.638 \\
\hline Santa Cruz & 5.021 & 2.389 & 3.725 & 2.746 & 3.483 & 2.988 \\
\hline Marizópolis & - & & 752 & 4.866 & 816 & 5.357 \\
\hline Santa Helena & 3.901 & 2.226 & 3.725 & 2.746 & 2.667 & 2.702 \\
\hline Vieirópolis & & & 3.758 & 914 & 4.049 & 996 \\
\hline $\begin{array}{l}\text { Poço de J osé de } \\
\text { Moura }\end{array}$ & & & 2.535 & 994 & 2.553 & 1.425 \\
\hline Poço Dantas & - & & 3.111 & 717 & 2.775 & 977 \\
\hline São Francisco & - & & 2.417 & 1.047 & 2.001 & 1.363 \\
\hline Bernardino Batista & - & & 2.220 & 339 & 2.217 & 858 \\
\hline Lastro & - & & 2. 036 & 1.082 & 1.506 & 1.335 \\
\hline Santarém & 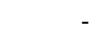 & & 1.930 & 638 & 1.775 & 840 \\
\hline Bom J esus & 1.220 & 515 & 1.374 & 819 & 1.408 & 991 \\
\hline Total & 80.925 & 113.754 & 73.172 & 133.739 & 75.852 & 143.481 \\
\hline
\end{tabular}

\section{Imagens de satélite}

As imagens do TM-Landsat 5 empregadas no estudo, foram adquiridas junto à Divisão de Geração de Imagens (DGI) do Instituto Nacional de Pesquisa Espaciais (INPE). E diante da grande disponibilidade de imagens de diferentes datas, os critérios adotados para a escolha das imagens foram: (i) a menor cobertura de nuvens possível e (ii) pertencerem ao mesmo período do ano. Neste sentido foram selecionadas as cenas do dia 6 de outubro de 2010, 2 de outubro de 1997, 24 de setembro de 1994 e 7 de outubro de 1987. Além dessas imagens outras cenas da mesma área foram adquiridas diretamente da National Aeronautics and Space Administration (NASA) com o objetivo de se obter retificação geométrica das imagens selecionadas.

As cenas do satélite Landsat 5 se caracterizam por 6 bandas multiespectrais no domínio do visível e infravermelho próximo, com resolução espacial de $30 \mathrm{~m}$ e uma banda termal com $120 \mathrm{~m}$ de resolução espacial. Cada banda representa a resposta da superfície terrestre em certa faixa espectral (Chander et al., 2009).

O pré-processamento inclui as etapas de reamostragem dos pixels, correção geométricas das imagens, mosaico e redução da dimensionalidade, operações essas realizadas no software ErdasImage $^{\circledR} 9.0$ cujos procedimentos, no entanto, não adicionam informações aos dados mas apenas preparam as imagens para as etapas de processamento.

A reamostragem dos pixels é necessária em virtude das diferentes resoluções entre as bandas espectrais, uma vez que todas as operações são realizadas "pixel a pixel". Este procedimento apenas redimensiona os pixels de menor resolução espacial para que eles tenham o mesmo tamanho dos pixels de maior resolução espacial. A correção geométrica tem, como objetivo, melhorar a qualidade das imagens para análise visual e processamento digital das imagens, além de minimizar os efeitos de deslocamento unidimensional do relevo e de distorção tangencial da escala.

O mosaico é um procedimento necessário em razão da área de estudo estar localizada entre duas cenas. Este procedimento permite a fusão entre as cenas, gerando uma única imagem. A redução da dimensionalidade permite selecionar apenas a área de interesse, reduzindo o tamanho do arquivo e, em consequência, o tempo de processamento.

As etapas metodológicas para o processamento das imagens estão descritas no fluxograma da Figura 3. O processamento se inicia após o pré-processamento das
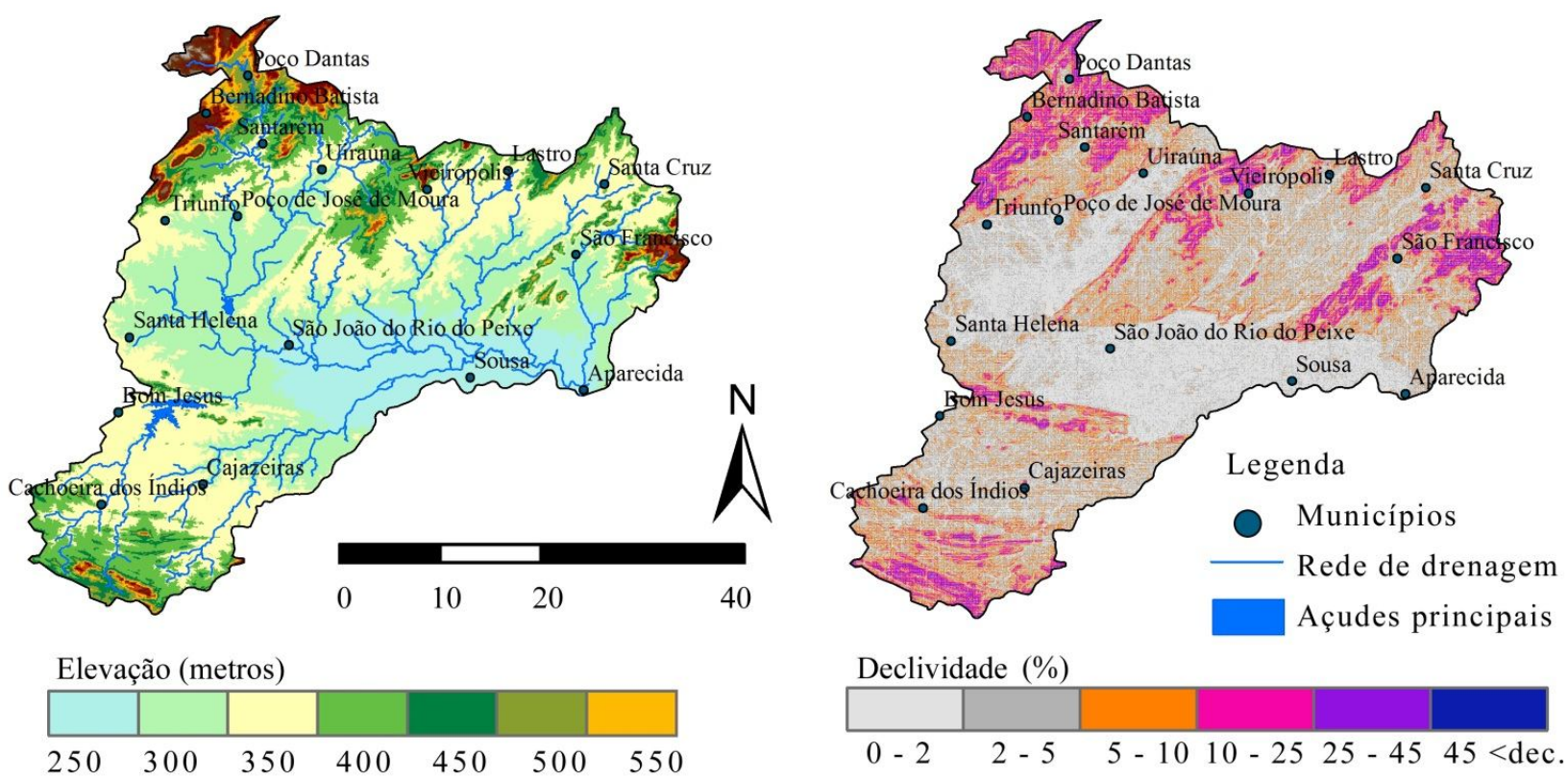

Declividade (\%)
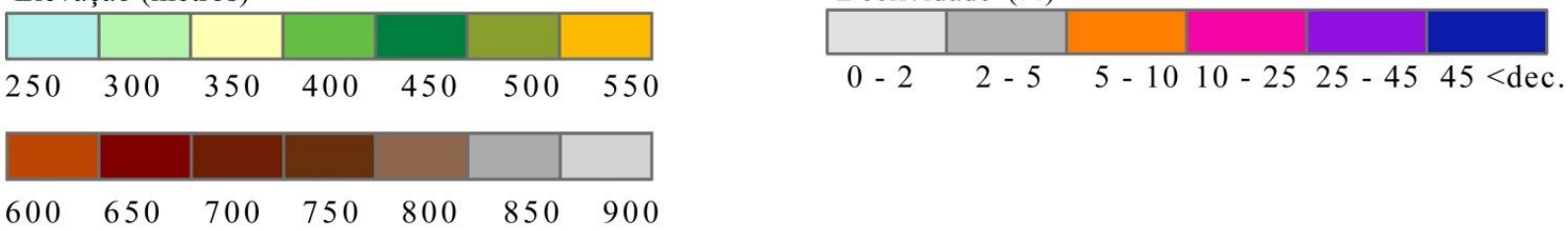

Figura 2. Mapa topográfico, municípios, rede de drenagem e açudes principais 


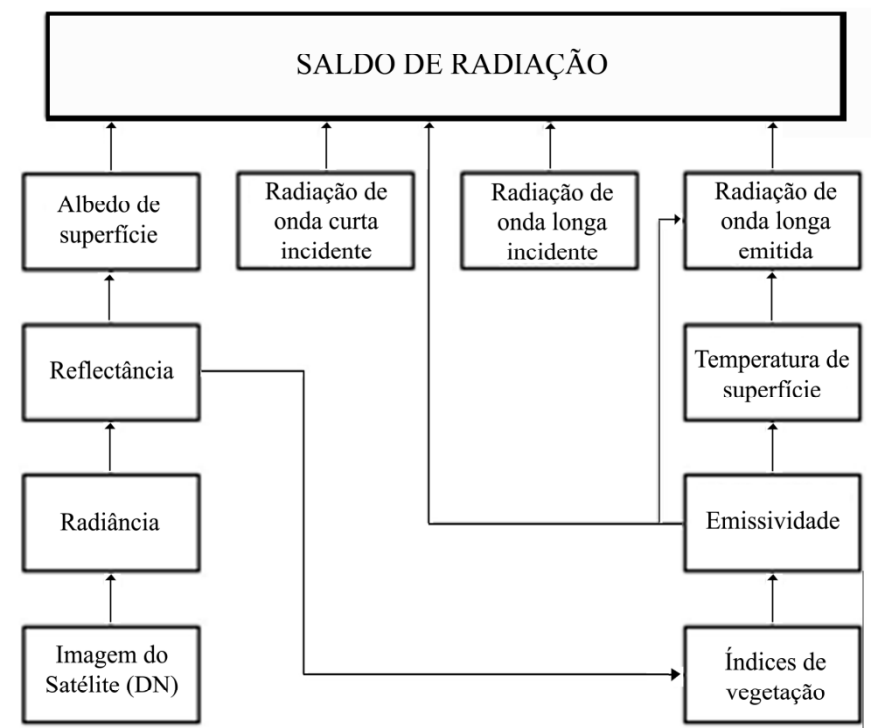

Figura 3. Fluxograma das etapas de processamento

imagens. Nas etapas de processamento são aplicadas as operações para o cálculo da radiância espectral, reflectância espectral, índices de vegetação, albedo da superfície, temperatura da superfície e saldo de radiação, operações essas realizadas no software ErdasImage ${ }^{\circledR}$ 9.0.

O cálculo da radiância espectral e a refletividade espectral foram realizados conforme os procedimentos descritos em Chander et al. (2009). Este procedimento visa assegurar que as mudanças identificadas no comportamento espectral, no tempo e no espaço, estejam estritamente ligadas à interação da onda eletromagnética com o alvo, eliminado quaisquer contribuições do ambiente na reflectância do alvo registrada pelo sensor.

Os índices de vegetação NDVI (normalized difference vegetation index) e EVI (enhanced vegetation index) foram calculados conforme metodologia apresentada em Jiang et al. (2008) e o índice de vegetação LAI (leaf area index) foi calculado segundo a metodologia apresentada em Allen et al. (2007). As etapas que envolvem o cálculo do albedo da superfície, temperatura da superfície e saldo de radiação, foram calculadas a partir dos procedimentos documentados em Di Pace et al. (2008) e Silva et al. (2005).

Para estudar a correlação existente entre os produtos obtidos pelas técnicas de processamento digital de imagens e a precipitação foram adquiridos, então, junto à Agência Executiva de Gestão das Águas do Estado da Paraíba (AESA) e na Unidade Acadêmica de Ciências Atmosféricas (UACA) da Universidade Federal de Campina Grande (UFCG), os dados pluviométricos diários registrados nos postos situados no interior da área de estudo.

Os dados diários foram agregados em intervalos de 15 dias, até o total de 120 dias antes da obtenção da imagem. Esses dados foram espacializados a partir do módulo de análise espacial (spatial analyst) do Sistema de Informação Geográfica ArcGis $9.2^{\circledR}$ através do método de interpolação do inverso do quadrado da distância (IQD), quando então foi obtida média espacial da precipitação para cada momento utilizado na interpolação.

Os dados topográficos da região foram gerados a partir do Modelo de Elevação Digital (DEM), obtido a partir das imagens do Shuttle Radar Topography Mission (SRTM), adquiridas no Consultative Group on International Agriculture Research Consortium for Spatial Information (CGIAR - CIS).

Os dados dessas imagens possuem a informação de elevação do terreno para cada pixel, com resolução espacial de $90 \mathrm{~m}$. No presente estudo o DEM foi reamostrado para resolução de $30 \mathrm{~m}$, de modo a compatibilizá-lo com as imagens TMLandsat 5 .

Devido à influência da topografia na análise dos resultados gerou-se, a partir de técnicas de geoprocessamento, a declividade do terreno (Figura 2) para cada pixel da imagem. A Tabela 2 apresenta as classes de declividade às quais os pixels foram agrupados e a porcentagem da área da bacia ocupada por cada classe.

Tabela 2. Classes de declividade e percentual da área da bacia para cada classe

\begin{tabular}{cc}
\hline Classe de declividade () & $\%$ da área \\
$0-2$ & 45,99 \\
$2-5$ & 27,65 \\
$5-10$ & 15,28 \\
$10-25$ & 8,69 \\
$25-45$ & 2,33 \\
Declividades $>45$ & 0,06 \\
\hline
\end{tabular}

Cada classe da imagem de declividade foi convertida em polígono, visando facilitar a extração de médias espaciais dos índices (NDVI, LAI e EVI), temperatura da superfície, albedo da superfície e saldo de radiação. Dos polígonos foram retiradas as áreas correspondentes à superfície com presença de água visando-se evitar, desta maneira, que valores atribuídos a essa superfície possam interferir na média espacial de cada classe.

\section{RESULTADOS E DISCUSSÃO}

As regiões de clima semiárido apresentam vegetação mais susceptível a mudanças, respondendo rapidamente à presença ou falta de chuvas. Tendo em vista a influência da precipitação sobre a vegetação, escolheu-se o período de sua menor ocorrência para que as análises não sejam influenciadas pelas modificações da paisagem causadas por chuvas ocorridas antes da passagem do satélite sobre a região de estudo.

A Figura 4 mostra a média espacial da precipitação acumulada para cada mês dos anos estudados, podendo-se observar a variação da precipitação ao longo dos anos. O período compreendido entre a última semana de setembro e a primeira semana de outubro foi escolhido por apresentar, em comum, para todos os anos, um período de baixa precipitação antecedente à obtenção das imagens.

Na Tabela 3 tem-se a média espacial da precipitação acumulada para cada intervalo de tempo antecedente as passagens do satélite na região de estudo. Pode-se observar, de maneira geral, que não houve chuvas significativas para os primeiros trinta dias que antecedem a captura das imagens pelo sensor. Desta forma, a vegetação apresenta baixo nível de umidade não interferindo na resposta dos alvos nos canais de refletividade. 


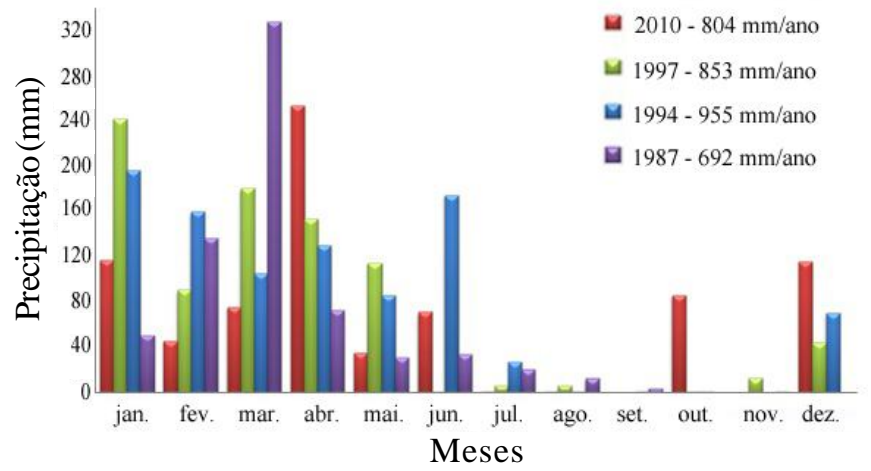

Figura 4. Média espacial da precipitação acumulada para cada mês

Tabela 3. Média espacial da precipitação acumulada para cada intervalo

\begin{tabular}{rcccccccccc}
\hline & \multicolumn{10}{c}{ Dias antecedentes à aquisição das imagens } \\
\cline { 2 - 12 } Ano & $\mathbf{0}$ & $\mathbf{1 5}$ & $\mathbf{3 0}$ & $\mathbf{4 5}$ & $\mathbf{6 0}$ & $\mathbf{7 5}$ & $\mathbf{9 0}$ & $\mathbf{1 0 5}$ & $\mathbf{0}$ & $\mathbf{0}$ \\
& $\mathbf{a}$ & $\mathbf{a}$ & $\mathbf{a}$ & $\mathbf{a}$ & $\mathbf{a}$ & $\mathbf{a}$ & $\mathbf{a}$ & $\mathbf{a}$ & $\mathbf{a}$ & $\mathbf{a}$ \\
& $\mathbf{1 5}$ & $\mathbf{3 0}$ & $\mathbf{4 5}$ & $\mathbf{6 0}$ & $\mathbf{7 5}$ & $\mathbf{9 0}$ & $\mathbf{1 0 5}$ & $\mathbf{1 2 0}$ & $\mathbf{9 0}$ & $\mathbf{1 2 0}$ \\
$\mathbf{2 0 1 0}$ & $\mathbf{0 , 0}$ & $\mathbf{0 , 0}$ & $\mathbf{0 , 7}$ & $\mathbf{0 , 0}$ & $\mathbf{0 , 0}$ & $\mathbf{0 , 2}$ & $\mathbf{2 2 , 4}$ & 41,3 & 0,9 & \multicolumn{1}{c}{41,3} \\
1997 & 0,0 & 0,0 & 0,0 & 5,8 & 2,0 & 3,9 & 0,2 & 0,0 & 11,7 & 11,9 \\
1994 & 0,2 & 0,3 & 0,4 & 4,3 & $\mathbf{7 , 6}$ & 62,6 & 74,4 & 69,5 & 75,4 & 219,3 \\
1987 & 0,0 & 3,0 & 14,0 & 0,2 & 4,8 & 12,8 & 12,0 & 21,9 & 34,8 & 68,7 \\
\hline
\end{tabular}

Para outros períodos que antecederam a aquisição das imagens pelo TM-Landsat 5 , observa-se que a chuva ocorre de forma variada. Ordenando-se os anos mais chuvosos para o período de noventa dias antecedentes à passagem do sensor, têm-se os anos de 1994, 1987, 1997 e 2010 e, para o período de cento e vinte dias da passagem do sensor, tem-se a seguinte ordem: 1994, 1987, 2010 e 1997.

A cobertura vegetal em áreas secas está altamente correlacionada com a precipitação, motivo pelo qual é de se esperar que os anos que apresentaram maior índice pluviométrico antes da passagem do sensor sejam exatamente os que apresentam maior aumento da cobertura vegetal; no entanto, alguns processos antrópicos, como a extração de madeira sem manejo sustentável, podem ser mais expressivos do que a resposta da vegetação ao regime pluvial.

Os índices de vegetação ressaltam, dentre outras coisas, o comportamento espectral da vegetação em relação ao solo e a outros alvos da superfície terrestre. Os índices de vegetação NDVI, IAF e EVI foram então utilizados para demonstrar o comportamento das mudanças temporal e espacial da vegetação, na bacia de estudo.

Na Figura 5 estão apresentados os mapas de NDVI para os anos estudados. Confrontando os resultados obtidos para as datas estudadas observa-se que as áreas com maior altitude e declividade (Figura 2), tanto ao norte como ao sul, permaneceram mais vegetadas (NVDI > 0,2) ocorrendo, inclusive, ganho em intensidade e área do recobrimento da vegetação (maior presença de valores entre 0,3 e 0,4 ).

A Figura 6 apresenta o gráfico dos valores da média espacial de NDVI para cada classe de declividade, acompanhando a evolução das mudanças na cobertura do solo na bacia. Percebese, daí, o aumento dos valores de NDVI para todos os anos e classes analisados, corroborando com as análises realizadas para os mapas de NDVI (Figura 5).
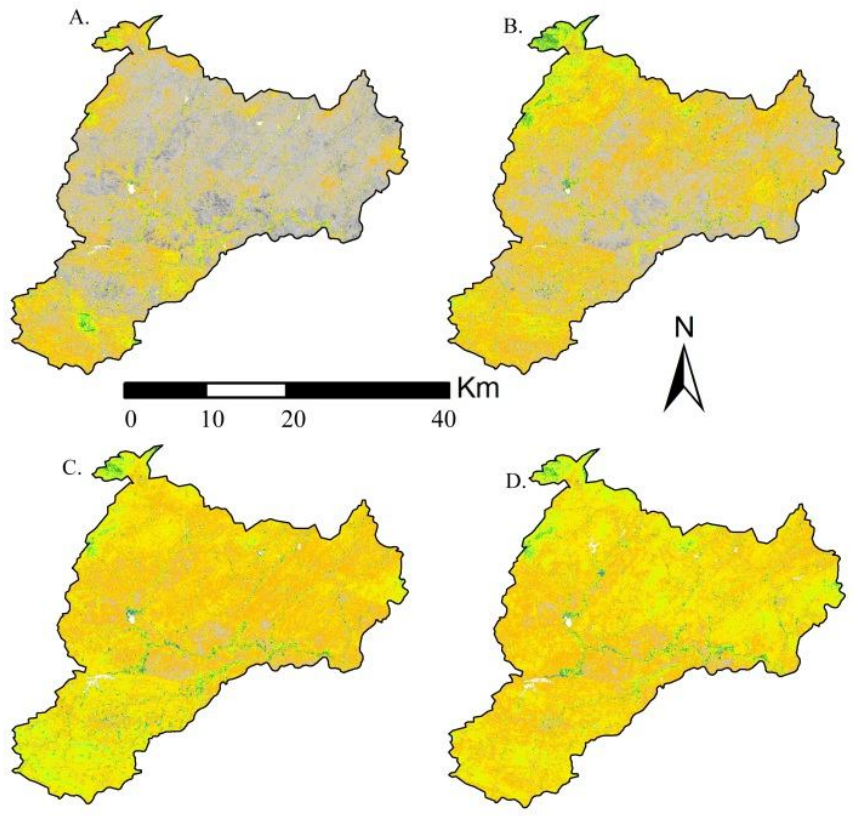

Legenda
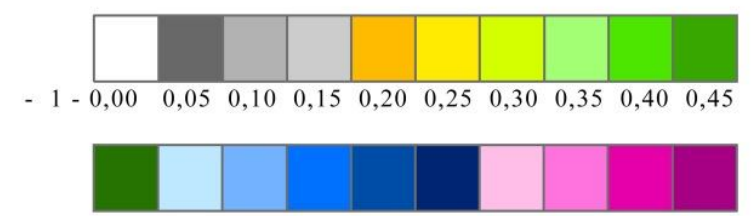

$\begin{array}{llllllllll}0,50 & 0,55 & 0,60 & 0,65 & 0,70 & 0,75 & 0,80 & 0,85 & 0,90 & 0,95\end{array}-1$

Figura 5. M apa de índice de vegetação N DVI (A) em 07 de outubro de1987, (B) em 24 de setembro de 1994, (C) em 02 de outubro de 1997 e (D) em 06 de outubro de 2010

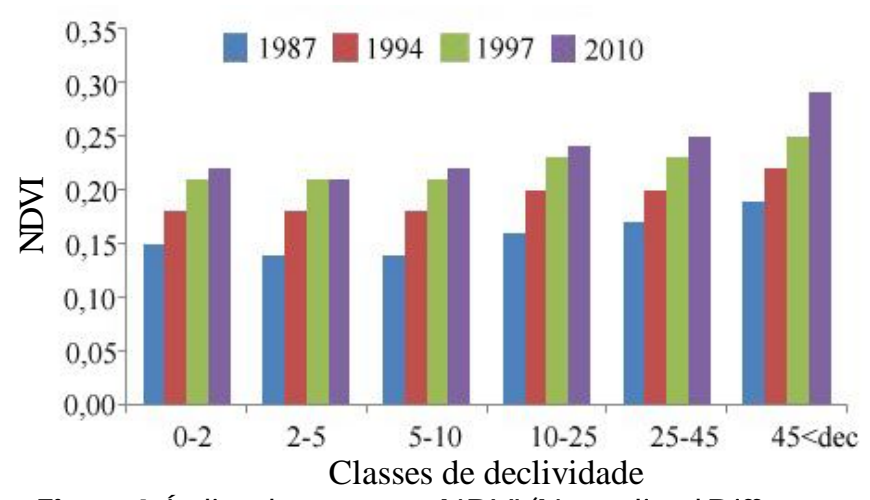

Figura 6. Índice de vegetação N DVI (N ormalized Difference Vegetation Index) e declividade

O índice de vegetação LAI, apresentado na Figura 7, é um indicador de biomassa da vegetação, representado em cada pixel da imagem. Com maior intensidade de contraste as imagens deste índice de vegetação mostram as mesmas modificações na cobertura vegetal apresentadas pelo NDVI.

Observa-se aumento gradativo dos valores de LAI para as imagens (Figura 7), partindo sempre das regiões de maior declividade para as de menor declividade, sendo essas correspondentes, em grande parte, às áreas com maiores altitudes (Figuras 2 e 8).

Em algumas áreas ao longo das regiões ribeirinhas e próximas aos reservatórios também é perceptível o aumento 

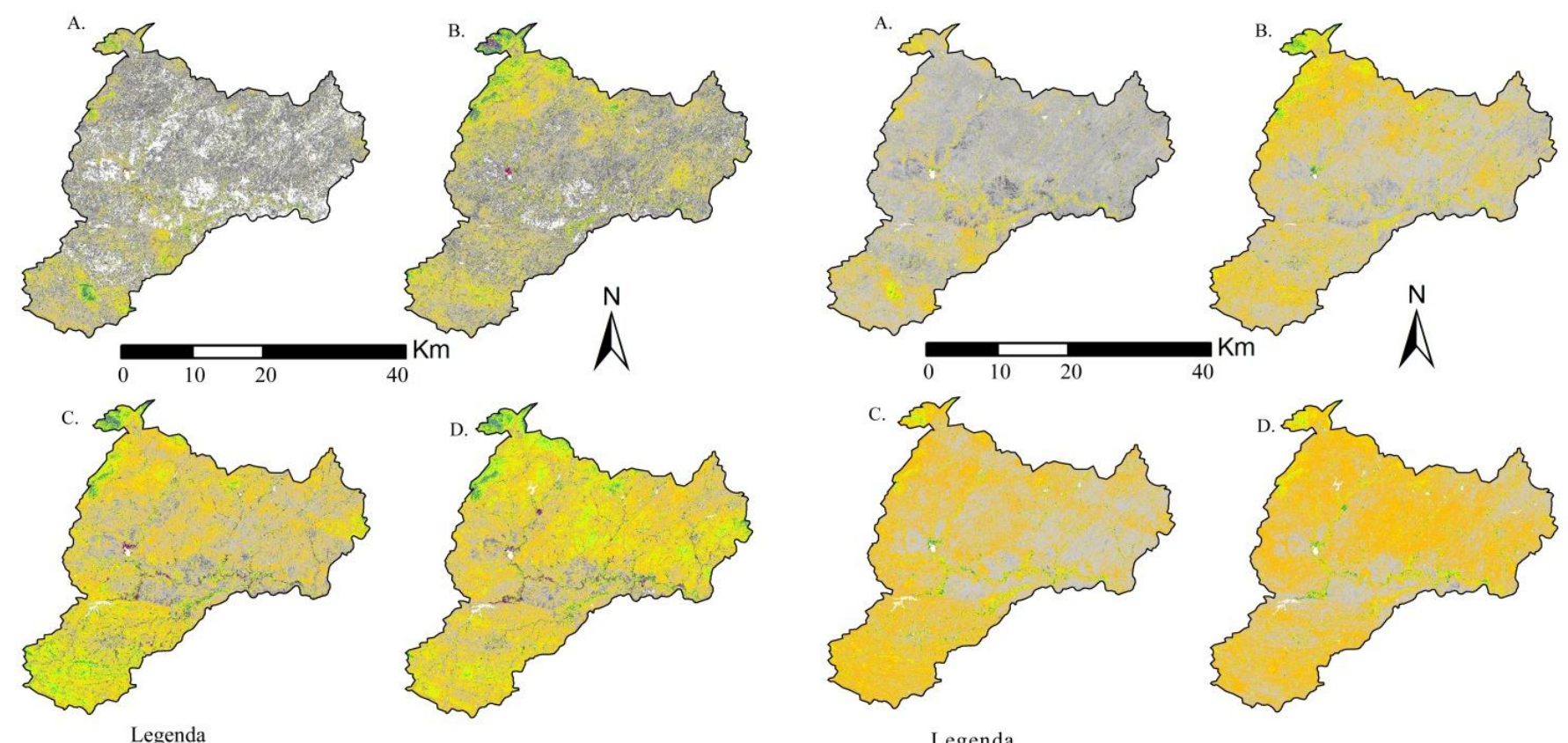

Legenda
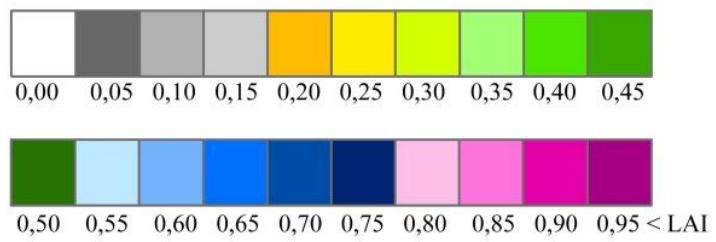

Figura 7. Mapa de índice de vegetação LAI (Leaf Area Index) (A) em 07 de outubro de1987, (B) em 24 de setembro de 1994, (C) em 02 de outubro de 1997 e (D) em 06 de outubro de 2010

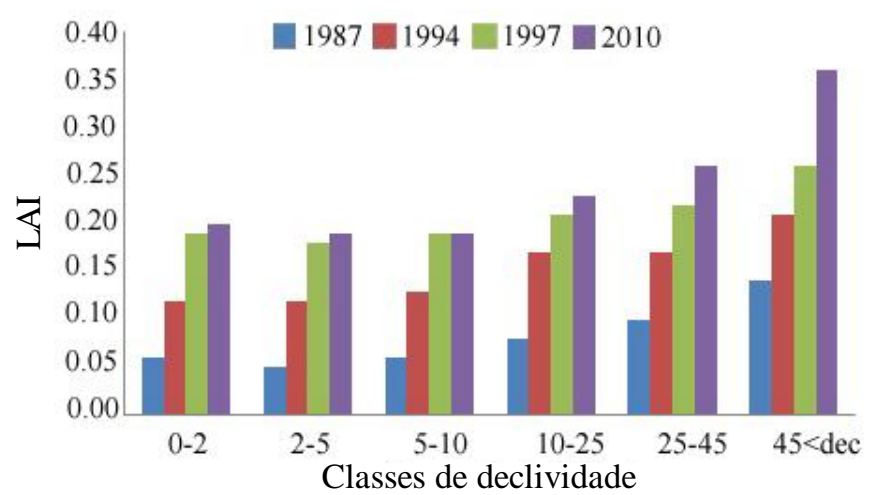

Figura 8. Índice de área foliar (LAI) e declividade

dos valores deste índice (Figura 2). Tal aumento corresponde às áreas com lavouras irrigadas e à presença da vegetação ciliar, que se mantêm verdes, em contraste com as áreas agrícolas em pousio e de pastagem que permanecem secas nesta época do ano. Referidas áreas estão mais evidentes nas imagens de 1997 (Figura 7 C) e 2010 (Figura 7 D).

A Figura 9 apresenta o índice de vegetação EVI, o qual ressalta o dossel da vegetação. Utilizam-se, neste índice, as bandas 1, 3 e 4 dos canais de refletividade do sensor TM, segundo o trabalho de Jiang et al. (2008). Este índice apresenta coeficientes de correção para os efeitos atmosféricos para as bandas 1 e 3; desta forma, as análises realizadas a partir deste índice não sofrem influência das variações atmosféricas.

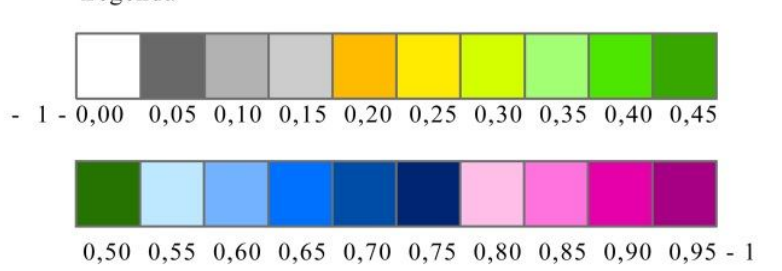

Figura 9. Mapa de índice de vegetação EVI (Enhanced vegetation index) (A) em 07 de outubro de 1987, (B) em 24 de setembro de 1994, (C) em 02 de outubro de 1997 e (D) em 06 de outubro de 2010

Os resultados apresentados pelo índice de vegetação EVI, acompanham a tendência observada para os índices de vegetação NDVI e LAI, quando se percebe o aumento da cobertura vegetal ao longo dos anos analisados. Contudo, o gráfico apresentado na Figura 10 mostra que os acréscimos encontrados na cobertura vegetal foram mais intensos no período de 1987a 1997 e se mantiveram praticamente constante no período de 1997 a 2010.

Analisando a Tabela 1 e se comparando os dados censitários de 1991 e 2000, pode-se constatar redução da população rural, nesta região. Com referência aos dados dos censos de 2000 e

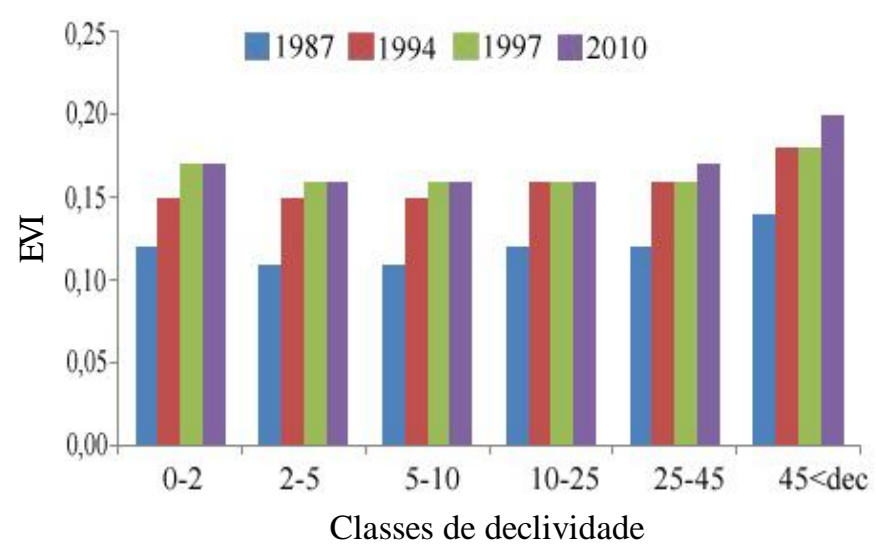

Figura 10. Enhanced vegetation index (EVI) e declividade 
2010, percebe-se um pequeno crescimento populacional que pode ser considerado irrelevante neste segundo período.

A redução na população rural ocasiona menor pressão antrópica ao ambiente, decorrente das atividades agrárias e pecuárias. As terras menos produtivas são abandonadas, permitindo que a vegetação nativa volte a ocupar essas áreas. A permanência e a intensificação da cobertura vegetal nas áreas mais altas e declivosas podem estar refletindo a menor pressão antrópica ao ambiente, pois são áreas mais remotas e de difícil acesso, fato também observado por Silva et al. (2003) na Bacia do Açude Namorado, em São João do Cariri, PB.

Apesar dos aumentos na cobertura da vegetação da bacia percebe-se, nas áreas centrais ao longo da rede de drenagem do Rio do Peixe (Figura 2), que os valores encontrados para os índices de vegetação são sempre mais baixos para todos os anos analisados. Áreas como essas podem trazer prejuízos à bacia, como um todo, uma vez que o período chuvoso nesta região é concentrado em um período de quatro meses, com precipitações de grande intensidade (Figura 4). Neste sentido, essas águas colidem com solo pouco protegido que se encontra com baixa cobertura vegetal, carreando sedimentos para os corpos d'água e retirando nutrientes do solo, tornando-os ainda mais pobres e o leito dos rios mais raso.

A Figura 11 apresenta os dados de temperatura de superfície da bacia para os momentos estudados. Observar que, de modo geral, a espacialização da temperatura ocorre de forma similar à

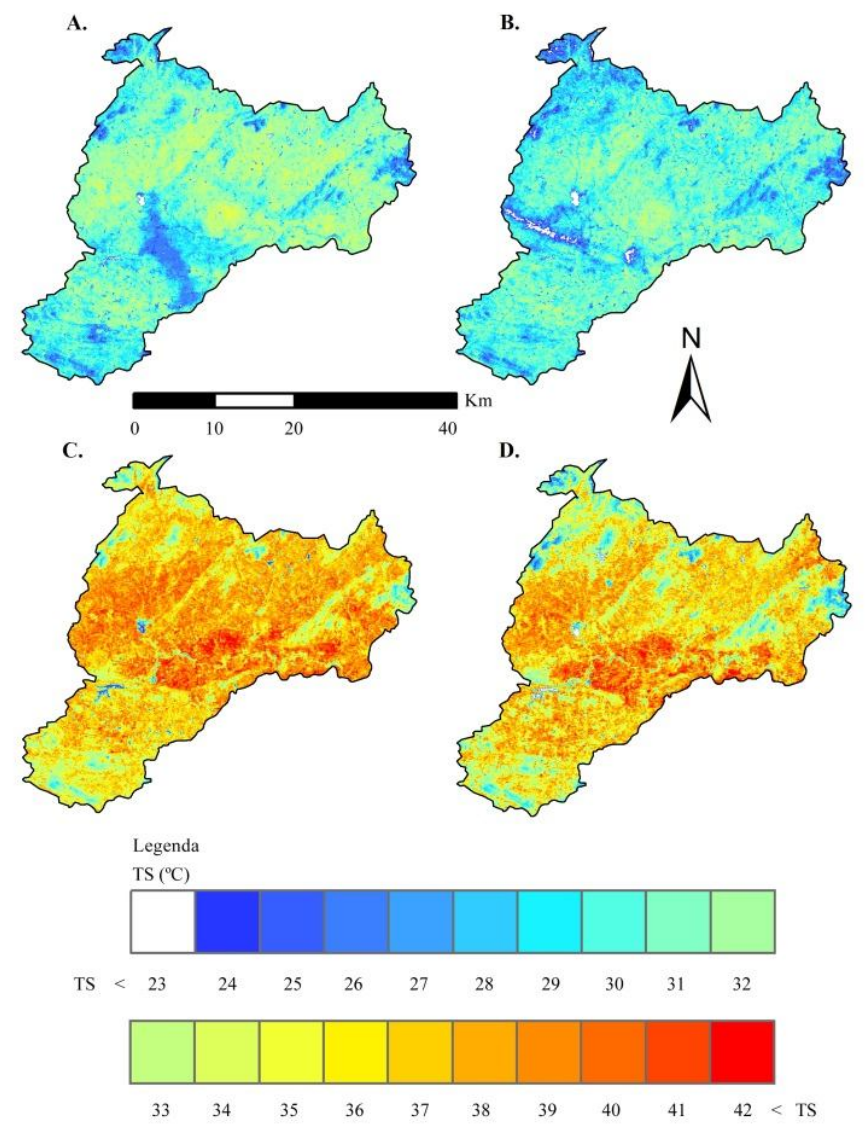

Figura 11. Mapa de Temperatura da superfície (A) em 07 de outubro de 1987, (B) em 24 de setembro de 1994, (C) em 02 de outubro de 1997 e (D) em 06 de outubro de 2010 distribuição da cobertura vegetal; contudo, proporcionalmente mais baixa, para os anos de 1987 (Figura 11A) e 1994 (Figura 11B).

A diferença de temperatura da superfície é função das propriedades físico-químicas dos corpos, atribuindo-lhes comportamento térmico diferenciado. Considerando que a incidência luminosa tenha sido a mesma, de vez que as datas da obtenção das imagens são muito próximas, já se previa que os anos mais quentes fossem os de 1987 (Figura 11A) e 1994 (Figura 11B), por apresentarem menores níveis de cobertura vegetal.

Observando a Tabela 3 constata-se que ocorreram variações da precipitação entre os anos, para o período de cento e vinte dias que antecedem a passagem do satélite pela região $(219,3$, 68,7, 41,3 e 11,9 mm), para os anos de 1994, 1987, 2010 e 1997, respectivamente. Relacionando-se os dados de precipitação com a temperatura, pode-se constatar que nos dois anos com mais chuvas antecedentes as temperaturas de superfície foram mais baixas.

Examinando os histogramas das imagens de temperatura da superfície pode-se identificar a média espacial da temperatura da superfície para toda a bacia. Analisando, de forma similar e ordenando os anos nos quais se obteve a menor média espacial da temperatura de superfície para os de maiores valores de temperatura, tem-se os anos de 1994 (Figura 11B), 1987 (Figura 11A), 2010 (Figura 11D) e 1997 (Figura 11C), que tiveram, respectivamente, as médias de $29,4,30,1,35,4$ e $36,4{ }^{\circ} \mathrm{C}$.

No gráfico apresentado na Figura 12 percebe-se que as variações na cobertura vegetal influenciaram na distribuição espacial da temperatura notando-se que, para um mesmo ano, as áreas mais vegetadas estão mais frias e vice-versa.

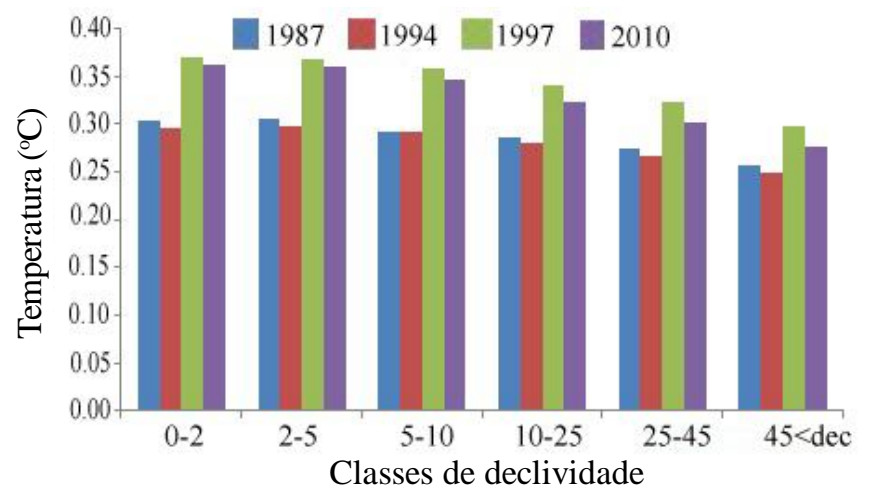

Figura 12. Temperatura da superfície e declividade

O período de maiores precipitações antes da passagem do satélite foi determinante para que as temperaturas nos anos de 1987 (Figura 11A) e 1994 (Figura 11B) estivessem mais frias que nos 1997 (Figura 11C) e 2010 (Figura 11 D). Percebe-se, na Figura 12, que este padrão foi mantido para todas as classes de declividade analisadas.

O Albedo de superfície apresentado na Figura 13, é a razão entre a radiação emitida e incidente pela superfície terrestre. Observa-se que os valores mais baixos correspondem aos corpos d'água que, por sua vez, apresentam pouquíssima refletividade (valores entre 0,00 e 0,03 ). Os valores entre 0,12 e 0,21 correspondem às áreas vegetadas e os valores acima de 

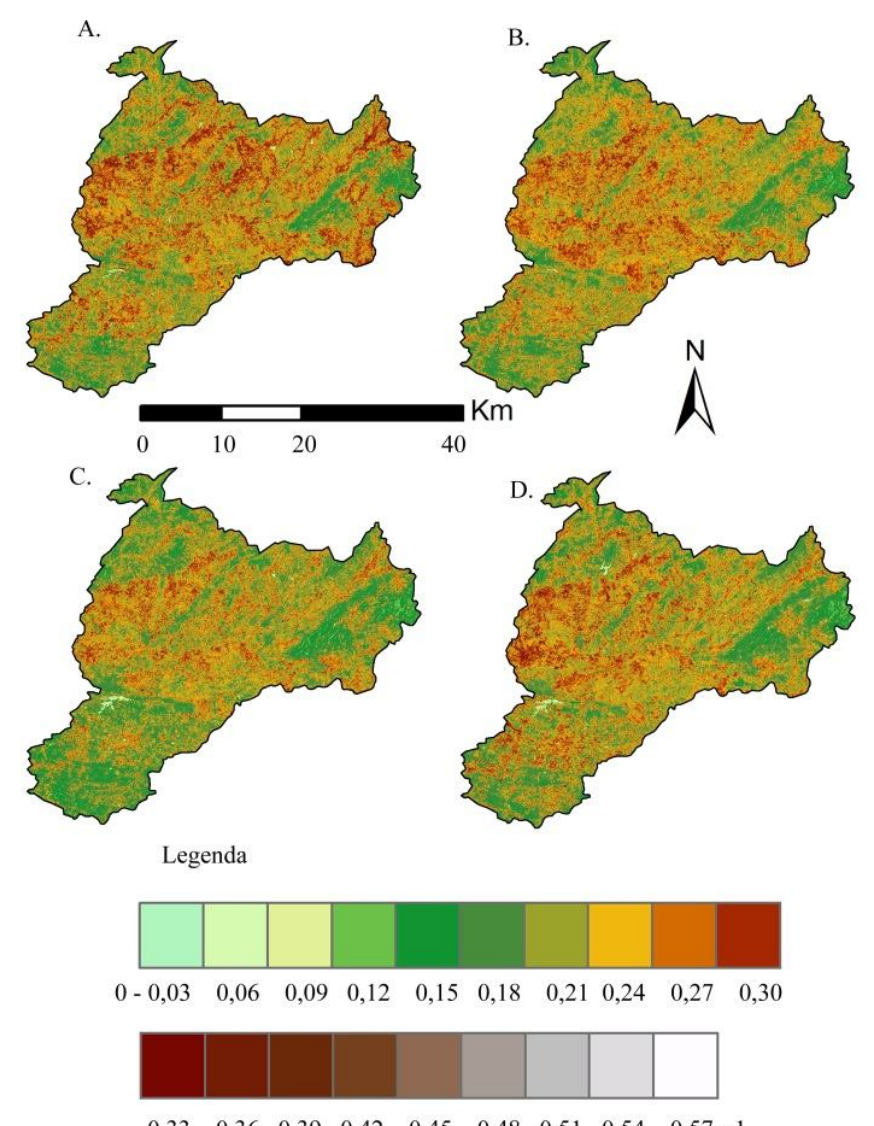

$\begin{array}{lllllllll}0,33 & 0,36 & 0,39 & 0,42 & 0,45 & 0,48 & 0,51 & 0,54 & 0,57-1\end{array}$

Figura 13. Mapa de albedo da superfície (A) em 07 de outubro de 1987, (B) em 24 de setembro de 1994, (C) em 02 de outubro de 1997 e (D) em 06 de outubro de 2010

0,24 se referem as áreas com pouca cobertura vegetal ou solo exposto.

Nota-se, de modo geral, que na imagem do ano de 2010 (Figura $13 \mathrm{D}$ ) os valores de albedo da superfície estão mais baixos que os encontrados no ano de 1987 (Figura 13 A), podendo-se destacar áreas na região norte da bacia que apresentam altos valores de albedo de superfície $(0,33$ - 0,39). Essas áreas estão menos intensas e em menor quantidade no ano de 2010.

Colocando a imagem de 1987 (Figura 13 A) como ponto de partida para as análises tem-se que para todos os outros períodos estudados foram encontrados valores menores de albedo para áreas cujos valores se encontravam, inicialmente, altos. A Figura 14 mostra o gráfico do albedo da superfície para

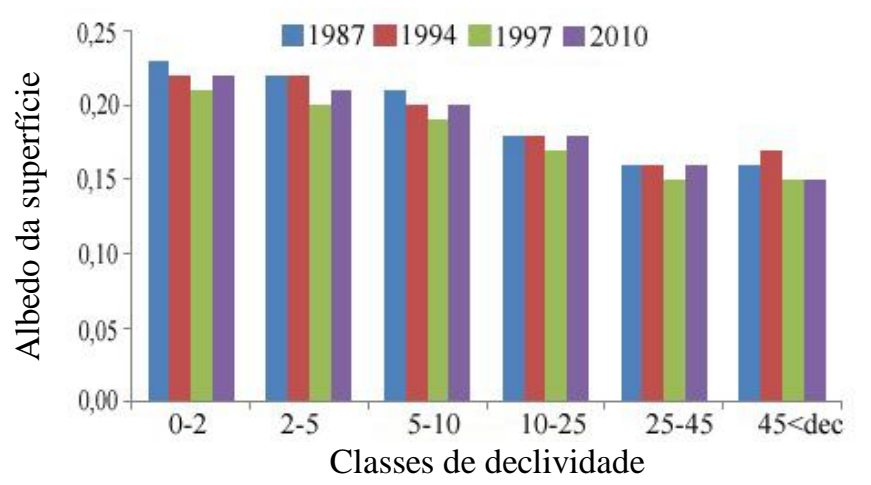

Figura 14. Albedo da superfície e declividade cada classe de declividade e se observa que os valores de albedo mais baixos são apresentados no ano de 1997, para todas as classes analisadas.

O saldo de radiação $(\mathrm{Rn})$, apresentado na Figura 15, corresponde à energia disponível no sistema analisado, ou seja, constitui a diferença entre os fluxos totais de radiação incidente, refletida e emitida pela superfície terrestre. As imagens obtidas correspondem praticamente ao mesmo período do ano, tendo os valores de radiação de onda curta incidentes, muito próximos.
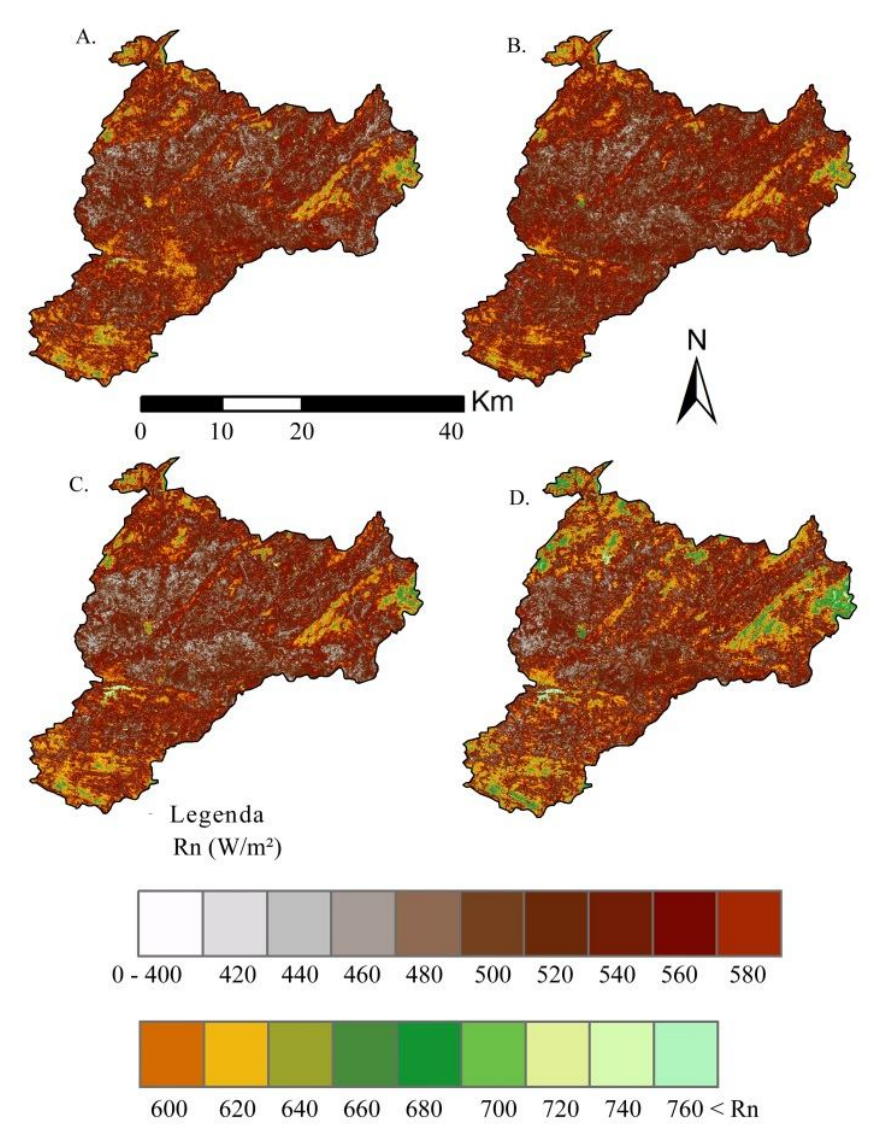

Figura 15. $M$ apa de saldo de radiação $(A)$ em 07 de outubro de 1987, (B) em 24 de setembro de 1994, (C) em 02 de outubro de 1997 e (D) em 06 de outubro de 2010

A radiação de onda curta refletida pela superfície depende da cobertura da superfície e regiões com solo desnudo vão refletir mais do que áreas vegetadas (albedo da superfície). A radiação de onda longa está à mercê, prioritariamente, da temperatura da superfície e do ar, visto que a maior emissão de radiação de onda longa ocorre nas áreas com maior temperatura de superfície.

Diante dos mapas de saldo de radiação $(\mathrm{Rn})$ apresentados na Figura 15 percebe-se que este componente mostra comportamento semelhante entre os anos analisados. Este fato também é apresentado no gráfico do saldo de radiação para cada classe de declividade (Figura 16).

Pode-se dizer que, para o período analisado, os efeitos decorrentes do aumento da cobertura vegetal foram compensados pelos menores níveis de temperatura da superfície para os anos em que os valores de cobertura vegetal estavam 


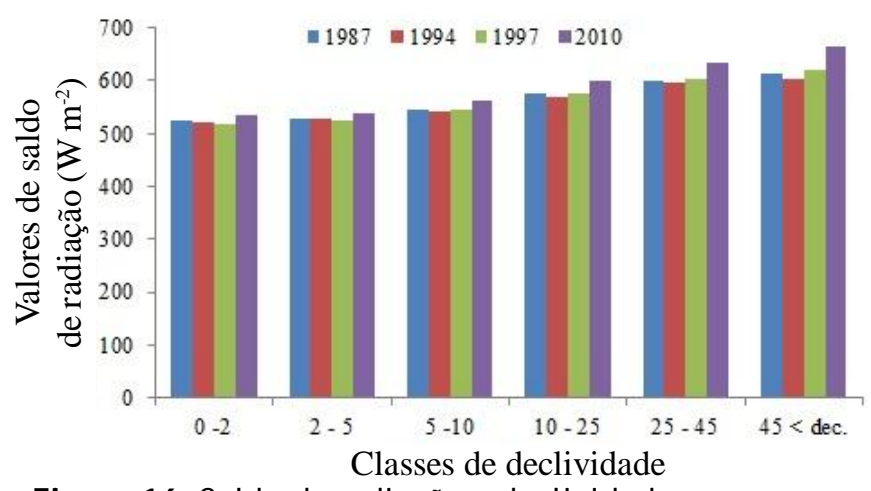

Figura 16. Saldo de radiação e declividade

mais baixos e nos quais se observa que os valores de saldo de radiação estão muito próximos para uma mesma classe de declividade.

\section{CONCLUSÕES}

1. A análise entre os períodos aponta para um aumento da cobertura vegetal na bacia,sendo as áreas de maior aumento mais altas e declivosas.

2. As mudanças na distribuição espacial da cobertura vegetal influenciam na distribuição espacial da temperatura da superfície mas não devem ser consideradas as únicas condições determinantes para explicar as variações de temperatura de superfície, ao longo do tempo.

3. O albedo de superfície mostra forte correlação com a cobertura do solo, sendo este um importante parâmetro em estudos ambientais.

4. O saldo de radiação se manteve praticamente constante durante o período analisado.

5. As imagens do sensor ThematicMapper do satélite Landsat 5, podem subsidiar análises ambientais; pode-se dizer, então, que sua resolução espacial média $(30 \mathrm{~m})$ atende às necessidades de trabalhos desta natureza.

\section{Agradecimentos}

Esta pesquisa se insere no âmbito do projeto "Geoprocessamento de dados termais e suas aplicações em estudos do regime pluviométrico no estado da Paraíba”, financiado pelo CNPq.

\section{LITERATURA CITADA}

Allen, R. G.; Tasumi, M.; Trezza, R. Satellite-based energy balance for mapping evapotranspiration with internalized calibration (METRIC) - Model. Journal of Irrigation and Drainage Engineering, v.133, p.380-394, 2007.

Alves, J. J. A.; Araújo, M. A.; Nascimento S. S. Degradação da caatinga: Uma investigação ecogeográfica. Revista Caminhos de Geografia, v.9, p.143-155, 2008.
Amiri, R.; Weng, Q.; Alimohammadi, A.; Alavipanah, S. K. Spatial-temporal dynamics of land surface temperature in relation to fractional vegetation cover and land use/cover in the Tabriz urban area, Iran. Remote Sensing of Environment, v.113, p.2606-2617, 2009.

Bradley, B. A.; Mustard, J. F. Identifying land cover variability distinct from land coverchange: Cheatgrass in the Great Basin. Remote Sensing of Environment, v.94, p.204-213, 2005.

Brasil. Ministério da Agricultura. I - Levantamento exploratórioreconhecimento de solos do estado da Paraíba. II Interpretação para uso agrícola dos solos do Estado da Paraíba. Rio de Janeiro, 1972. 670p. Boletim técnico, 15

Brinkmann, K.; Dickhoefer, U.; Schlecht, E.; Buerkert, A. Quantification of aboveground rangeland productivity and anthropogenic degradation on the Arabian Peninsula using Landsat imagery and field inventory data. Remote Sensing of Environment, v.115, p.465-474, 2011.

Carreiras, J. M. B.; Pereira, J. M. C.; Campagnolo, M. L.; Shimabukuro, Y. E. Assessing the extent of agriculture/ pasture and secondary succession forest in the Brazilian Legal Amazon using Spot Vegetation data. Remote Sensing of Environment, v.101, p.283-298, 2006.

Chander, G.; Haque, M. O.; Micijevic, E.; Barsi, J. A.AProcedure for radiometric recalibration of Landsat 5 TM Reflectiveband data. IEEE Geoscience and Remote Sensing Letters,v.48, p.556-574, 2010.

Chander, G.; Markham, B. L. Revised Landsat-5 TM radiometric calibration procedures, and post-calibration dynamic ranges. IEEE Geoscience and remote Sensing Letters, v.41, p.26742677, 2003.

Chander, G.; Markham, B. L.; Barsi, J. A. Revised Landsat-5 thematic mapper radiometric calibration. IEEE Geoscience and Remote Sensing Letters, v.4, p.490 - 494, 2007.

Chander, G.; Markham, B. L.; Helder, D. L. Summary of current radiometric calibration coefficients for Landsat MSS, TM, ETM+, and EO-1 ALI sensors. Remote Sensing of Environment, v.113, p.893-903, 2009.

Foody, G. M. Assessing the accuracy of land cover change with imperfect ground reference data. Remote Sensing of Environment, v.114, p.2271-2285, 2010.

Di Pace, F. T.; Silva, B. B. da; Silva, V. de P. R. da; Silva, S. T. A. Mapeamento do saldo de radiação com imagens Landsat 5 e modelo de elevação digital. Revista Brasileira de Engenharia Agrícola e Ambiental, v.12, p.385-392, 2008.

Gómez, C.; White, J. C.; Wulder, M. A. Characterizing the state and processes of change in a dynamic forest environment using hierarchical spatio-temporal segmentation. Remote Sensing of Environment, v.115, p.1665-1679, 2011.

Huang, C.; Goward, S. N.; Masek, J. G.; Thomas, N.; Zhu, Z.; Vogelmann, J. E. An automated approach for reconstructing recent forest disturbance history using dense Landsat time series stacks. Remote Sensing of Environment, v.114, p.183198, 2010.

IBGE - Instituto Brasileiro de Geografia e Estatística. http:// www.ibge.gov.br. 01 Mai. 2011. 
Jiang, Z.;Huete, A. R.; Didan, K.; Miura, T. Developmentof a two-band enhanced vegetation index without a blue band. Remote Sensing of Environment. v.112, p.3833-3845, 2008.

Liana, A. O.; Shimabukuro, Y. E. Monitoramento da cobertura terrestre: fenologia e alteraçõesantrópicas. In: Rudorff, B. F. T.; Shimabukur, Y. E.; Ceballos, J. C. (ed.) O sensor Modis e suas aplicações ambientais no Brasil. São José dos Campos: Silva Vieira, 2007. Cap. 14, p.185-205.

Morton, D. C.; DeFries, R. S.; Nagol, J.; Souza Jr., C. M.; Kasischke E. S.; Hurtt, G. C.; Dubayah, R. Mapping canopy damage from understory fires in Amazon forests using annual time series of Landsat and MODIS data. Remote Sensing of Environment, v.115, p.1706-1720, 2011.

Röder, A.; Hill, J.; Duguy, B.; Alloza, J. A.; Vallejo, R. Using long time series of Landsat data to monitor fire events and post-fire dynamics and identify driving factors. A case study in the Ayora region (Eastern Spain). Remote Sensing of Environment, v.112, p.259-273, 2008.
Schroeder, T. A.; Wulder, M. A.; Healey, S. P.; Moisen, G. G. Mappingwildfire and clearcut harvest disturbances in boreal forests with Landsat time series data. Remote Sensing of Environment, v.115, p.1421-1433, 2011.

Silva, A. P.; Chaves, I. B.; Sampaio, E. V. S. B. Cobertura vegetal da bacia hidrográfica do açude Namorado no Cariri Oriental Paraibano. Revista Agropecuária Técnica, v.24, p.47-59, 2003.

Silva, B. B.; Lopes, G. M.; Azevedo, P. V. de. Balanço de radiação em áreas irrigadas utilizando imagens Landsat 5 - TM. Revista Brasileira de Meteorologia, v.20, p.243-252, 2005.

Silva M. A.; Braga, C. C.; Aguiar M. J. N.; Nietzche, M. H.; Silva, B. B. Atlas climatológico do Estado da Paraíba. Projeto FINEP-UFPB, Campina Grande: FINEP/UFPB, 1984. 130p.

Stellmes, M.; Udelhoven, T.; Röder, A.; Sonnenschein, R.; Hill, J. Dryland observation at local and regional scale - Comparison of Landsat TM/ETM+ and NOAAAVHRR time series. Remote Sensing of Environment, v.114, p.2111-2125, 2010. 